\title{
Assessment of Selected Operating Characteristics of Polymer Composites with Non-Ferrous Materials Used in Friction Pairs
}

Jerzy Józwik

Mechanical Engineering Faculty, Lublin University of Technology, 36 Nadbystrzycka Street, 20-618 Lublin, Poland. Email: j.jozwik@pollub.pl

The paper investigates selected operating characteristics of polymer composites used in friction pairs. Eight polymer composites were investigated: PE with $\mathrm{MoS}_{2}$, PTFE with graphite, PPS with glass fibre, PA6-G with mineral oil, POM with aluminium, PTFE with MoS2, PTFE with bronze and PEEK with glass fibre. Results of hardness, compressive strength and porosity of the analysed composite materials are presented. The paper also presents test results of the friction force, friction coefficient, temperature near the friction node, and linear wear. The results are plotted in diagrams and discussed in the context of friction and wear assessment of the tested materials. On increasing the external load, all analyzed operating parameters of the friction process increase too. Among the tested polymer composites, the best results were obtained for PA6-G with mineral oil. PTFE-matrix composites despite their good results of the friction coefficient $\mu$-are less desired than POM with aluminium because their use is less cost-effective.

Keywords: Polymer Composites, Compressive Strength, Hardness, Porosity, Friction

\section{Introduction}

Polymers and polymer composites are more and more widely used in engineering as structural materials [1]. This results from the fact that they are lightweight, have very good mechanical and tribological properties [2, 3], high corrosion resistance, and ensure flexible processing [4-7] and self-lubrication [5-7], etc. Owing to these properties, composite materials are an alternative to traditional metals and ceramic materials. Assessment the operating characteristics of composite materials is an extensive area of research. In the papers [8-15] mechanical properties of polymer composites were analyzed in detail (dry sliding properties [8], thermal properties [9], influence o lubricants on the tribological properties [10-11], etc.). In particular, the tribological properties of friction nodes and the possibilities of using polymer composites in industry were analyzed in papers [12-15]. The results of these works are often compared to the properties of metal materials, whose tribological properties are described in [1622]. There are many polymers that are used as constituent materials in composites due to their properties. Very interesting results of creep behaviour of the polymer composite with false banana fibres (ensete ventricosum) were presented in the paper [23]. Additives have a significant effect on the properties of composite materials too. Fillers are usually made of glass, carbon [9], raphene-basalt fibre [10], nano- $\mathrm{Al}_{2} \mathrm{O}_{3}$ [12] and Kevlar fibres, diamond nanoparticles [8] as well as oil, molybdenum disulphide, bronze, aluminium alloys, etc. The mechanical properties of polymeric composite based on aluminium microparticles were analysed in paper [24] and mechanical characterisation of cetal/polymeric composite waste/metal sandwich panel in the work [25]. The properties of polymers and polymer composites are affected by processing temperature and a polymer's structure, particularly the mass fraction and contents of a crystalline phase, and the type of an additive. To give an example, the additives such as oil, grease and heat stabilizers can be used to shape the properties of PA6 as desired, which opens up a vast array of possibilities with respect to tailoring materials to specified applications [9-13].

From an operational point of view, it is vital that composite materials be inspected for their hardness, compressive strength, wear resistance, as well as internal defects and porosity [1, 5-15]. Along with mechanical properties, the chemical and thermal properties of composite materials are of significant importance too. Testing methods for plastics and composite materials are very similar to the methods used for traditional materials such as metals [16-22]

\section{Materials and methods}

This study investigated polymer composites used in friction nodes. 8 different composite materials with very good tribological properties and different mechanical properties were examined. Three of them had a PTFE matrix. PTFE with bronze, PTFE with graphite and PTFE with molybdenum disulphide $\left(\mathrm{MoS}_{2}\right)$ were analysed. The other composite materials included polyamide (PA6-G,) polyphenylene sulphide (PPS) and polyacetal (POM). PA6-G with mineral oil, POM with aluminium, polyether ether ketone (PEEK) with glass fibre, PPS with glass fibre, and $\mathrm{PE}$ with $\mathrm{M}_{\mathrm{O}} \mathrm{S}_{2}$ were tested. Specimens for friction, hardness and compression testing and computed tomography were prepared in compliance with the ASTM G 99 and DIN 50324 standards.

The investigation of operating characteristics of the above composite materials was conducted in stages. First, the materials were examined for their microhardness with the Wilson Hardness Tukon 2500. Hardness tests were performed by the Vickers and Shore methods. The specimens were subjected to static compression testing. The compressive tests were conducted on the universal testing machine Hung Ta ht-24002. The specimens were also inspected with the GE pheonix v|tome|x s, a versatile highresolution system for 2D X-ray inspection and 3D computed tomography. In particular, porosity of the analysed 
materials was assessed. 3 loads were applied in tribological tests: $10 \mathrm{~N}, 20 \mathrm{~N}$ and $30 \mathrm{~N}$. The sliding velocity was set equal to $450 \mathrm{rev} / \mathrm{min}$ while the sliding time was $1250 \mathrm{~s}$. The friction radius was maintained constant at $17 \mathrm{~mm}$ in all tests. One test cycle involved 9367 full revolutions of the specimen. The tests were conducted at the stabilized ambient temperature of $20^{\circ} \mathrm{C}$. Variations in the temperature near the friction node were observed. The maximum temperature in the vicinity of the friction node ranged from $26.4^{\circ} \mathrm{C}$ to $33.4^{\circ} \mathrm{C}$, depending on the friction pair materials. The constant parameters were time and sliding velocity, while the variables included load and composite type. A ball made of aluminium oxide $\left(\mathrm{Al}_{2} \mathrm{O}_{3}\right)$ was used in the tests. The friction radius $\mathrm{r}$ [mm] was set equal to $17 \mathrm{~mm}$ while the rotational speed of the specimen was 450 $\mathrm{rev} / \mathrm{min}$. Due to the fact that the friction process is timeconsuming, the sliding cycle time $t$ was set equal to 1250 [s]. The friction process was performed without lubrication. The following parameters were measured in the tests: friction force, linear wear and temperature in the contact zone. The tests were performed on the T-01M tester using the ball-on-disc method, in compliance with the ASTM G 99 and DIN 50324 standards.

\section{Results and discussion}

For the purpose of clarity, test results are divided into three groups. The first group contains the hardness results obtained for composite materials with a Teflon matrix. The second group comprises the hardness results of composites with their matrix made from PA6-G, POM and $\mathrm{PE}$. The third group includes the hardness results achieved by composite materials with a fibre glass reinforcement: PPS and PEEK.

\subsection{Hardness tests of composite materials}

Fig. 1 shows the hardness results of specimens that were also used in strength and tribological testing as well as computed tomography inspection. As can be observed in Fig. 1, PTFE with MoS2 achieved the highest microhardness by both methods (Shore D: 77-81 and HV2: 19.2-23.9), in spite of the fact that the addition of molybdenum disulphide itself does not lead to increased hardness. PTFE with bronze has the second highest hardness amounting to 7.0-8.7 (HV2) and 65.8-68.2 (Shore D). As expected, the bronze powder has a positive effect on the material's hardness.

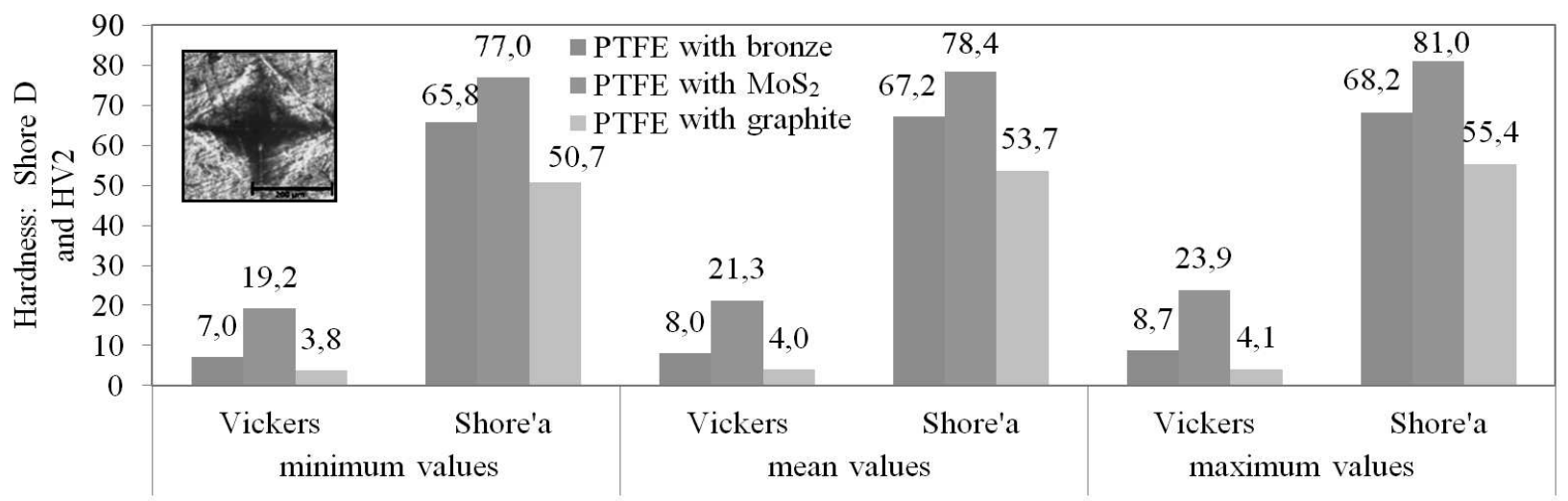

Fig. 1 Hardness of composite materials: PTFE with bronze, PTFE with $\mathrm{MoS}_{2}$, PTFE with graphite

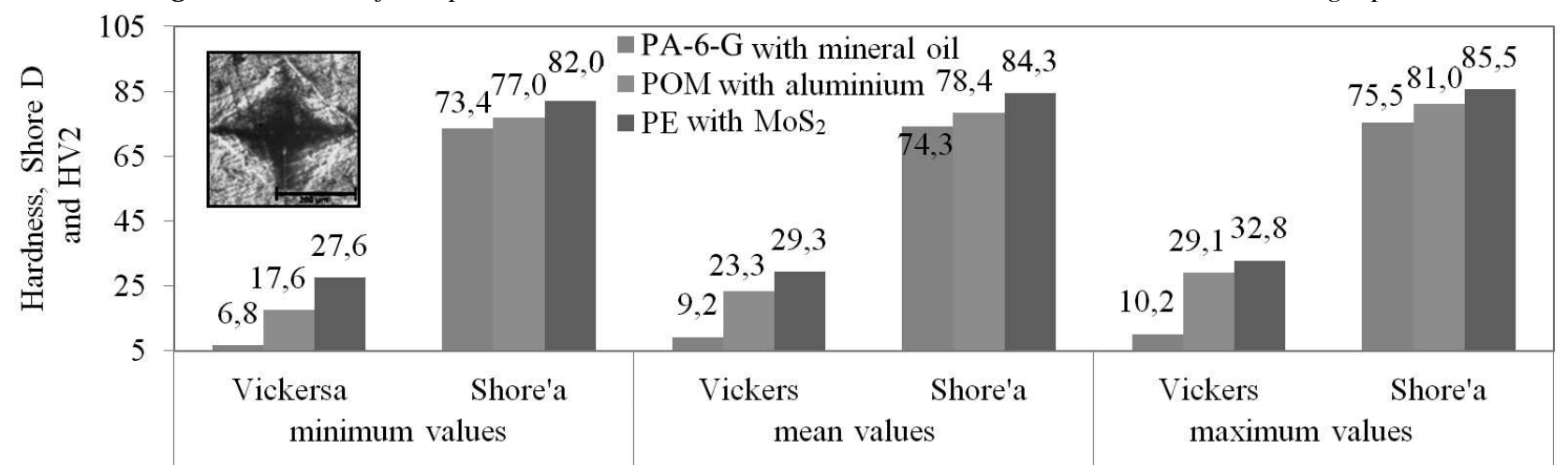

Fig. 2 Hardness of composite materials: PA-6-G with mineral oil, POM with aluminium, PE with MoS 2

Compared to graphite, its addition leads to a two-fold increase in hardness. The final material in this group, PTFE with graphite, exhibits the lowest microhardness amounting to 3.8-4.1 (HV2) and 50.7-55.4 (Shore D).

The diagram in Fig. 2 reveals that PE with $\mathrm{MoS}_{2}$ has the highest hardness $(27.6-32.8 \mathrm{HV} 2)$ out of all materials in this group. PA-6-G with mineral oil exhibits the lowest hardness (6.8-10.2 HV2 and 73.4-75.5 Shore D). The hardness results of POM with aluminium (Vickers and Shore D alike) are between those obtained for PA-6-
$\mathrm{G}$ with mineral oil and PE with $\mathrm{MoS}_{2}$. Fig. 3 compares two composite materials reinforced with glass fibre: PPS and PEEK. The filler's content in both composite materials was the same, i.e., 30\%. This enabled determining the effect of the matrix on the specimen's hardness. The highest mean hardness was achieved by PPS with fibre glass (26.7 HV2, 84.5 Shore D), whereas the mean hardness of PEEK with fibre glass is more than two times lower (11.7 HV2, 75.0 Shore D). 


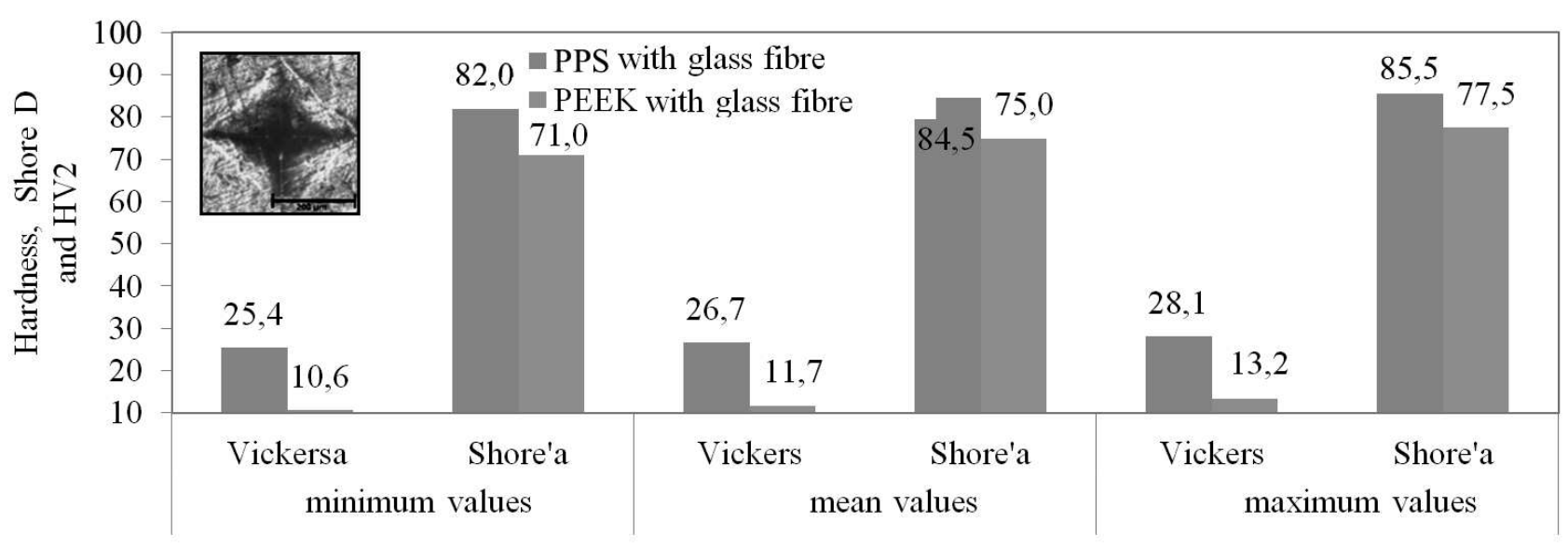

Fig. 3 Hardness of composite materials: PPS with glass fibre, PEEK with glass fibre

\subsection{Porosity tests}

Fig. 4. Shows the results of porosity of the analysed specimens. The objective of this measurement was to determine the total ratio of pore volume to a material's total volume.

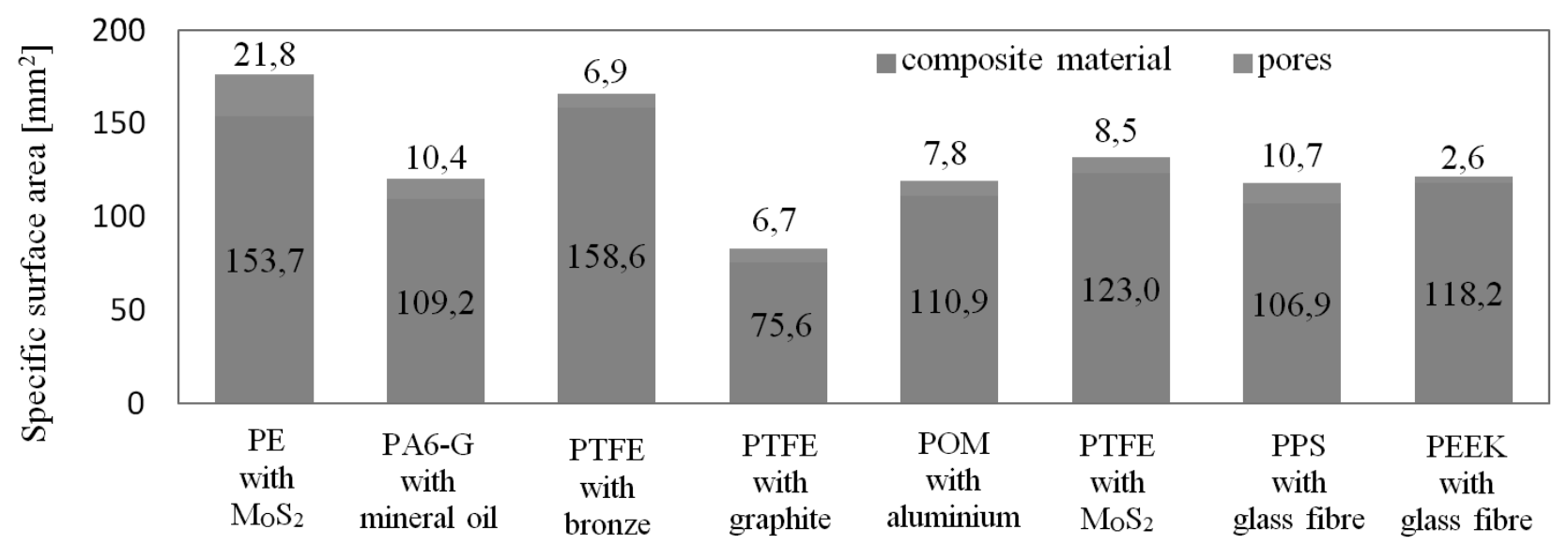

Fig. 4 Comparison of pore volume and total volume of the analyzed composite materials

The highest porosity, defined as the ratio of a porous material's air volume to a composite material's total volume, was obtained by $\mathrm{PE}$ with $\mathrm{M}_{\mathrm{O}} \mathrm{S}_{2}$, amounting to 0.14 (21.8/153.7). The second highest porosity of almost 0.1 was achieved by two composite materials: PPS with glass fibre $(10,7 / 106,9)$ and PA6-G with mineral oil $(10,4 / 109,2)$. PTFE with graphite $(6,7 / 75,6)$ and with $\mathrm{M}_{\mathrm{O}} \mathrm{S}_{2} \quad(8,5 / 123,0)$ as well as $\mathrm{POM}$ with aluminium $(7,8 / 110,9)$ have similar porosity that is close/equal to 0.07. Despite the highest material volume, PTFE with bronze does not stand out in terms of pore volume. The porosity of this composite material is merely 0.004 . PEEK with glass fibre exhibits the lowest porosity.

Fig. 5 shows the specimen sections in a binary (digital) form, where, for clarity, the pores are marked in yellow, the matrix in grey and the reinforcement in black. Thanks to the use of a higher contrast ratio, one can clearly observe that the fillers have different particle sizes. PE with $\mathrm{M}_{\mathrm{O}} \mathrm{S}_{2}$ has the highest number of pores. The maximum volume of air bubbles or voids is $0.1 \mu \mathrm{m}^{3}$. Filler particles are uniformly distributed in the matrix, which indicates isotopic structure and properties of the material. PA6-G with mineral oil contains a large number of pores $\left(10.41 \mathrm{~mm}^{3}\right)$ having the maximum volume of $0.25 \mu \mathrm{m}^{3}$. One can observe a sharp increase in the number of pores $(10,000)$ with a volume of $0.02 \mu \mathrm{m} 3$. PPS with glass fibre and PTFE with graphite have the same percentage of pore volume. In both cases, the pores have the maximum volume of $0.25 \mu^{3}$, and, once, the number of air bubbles sharply increases to 6,000 with a volume of 0.01 $\mu \mathrm{m}^{3}$.

POM with aluminium has pores with a volume of 0.25 $\mu \mathrm{m}^{3}$ and their number does not exceed 1000 . It can be observed that the number of pores linearly decreases with increasing their volume. PTFE with $\mathrm{M}_{\mathrm{O}} \mathrm{S}_{2}$ contains pores with the maximum volume of $0.5 \mu \mathrm{m}^{3}$, albeit their number is very low. There occurs a sharp increase in the number of pores $(8,000)$ with a volume of $0.02 \mu \mathrm{m}^{3}$. PTFE with bronze has the biggest pores, and their number does not exceed 250. The maximum observed volume of air bubbles is equal to $1.5 \mu \mathrm{m}^{3}$. PEEK with glass fibre consists of pores having the maximum volume of $0.25 \mu \mathrm{m}^{3}$. 
a)

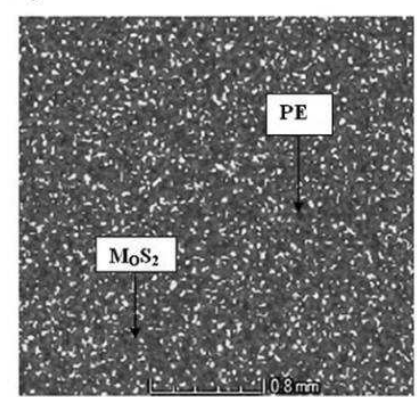

c)

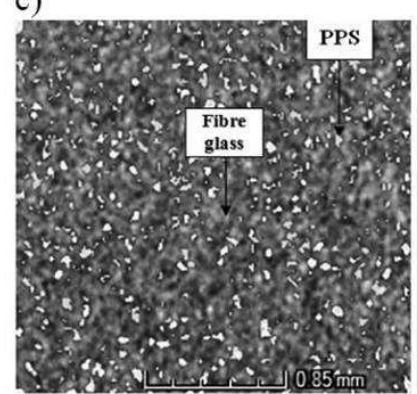

b)

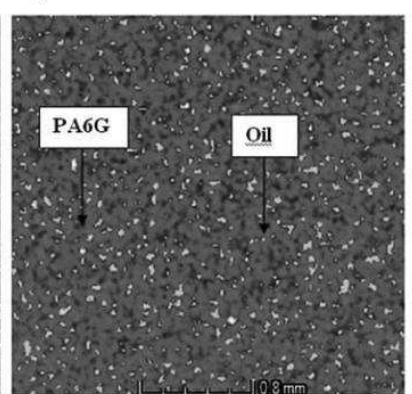

d)

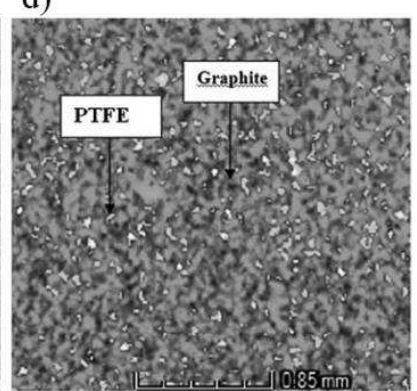

e)

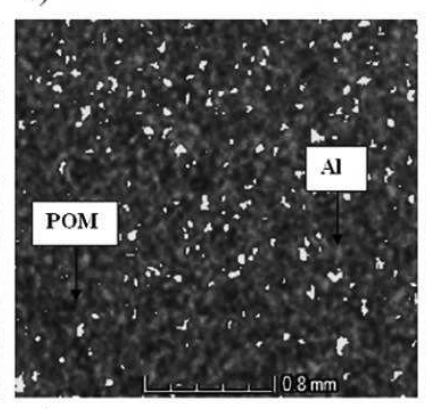

g)

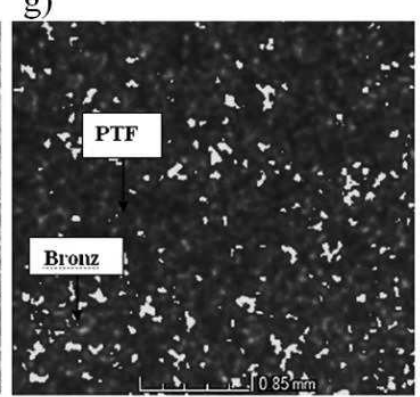

f)

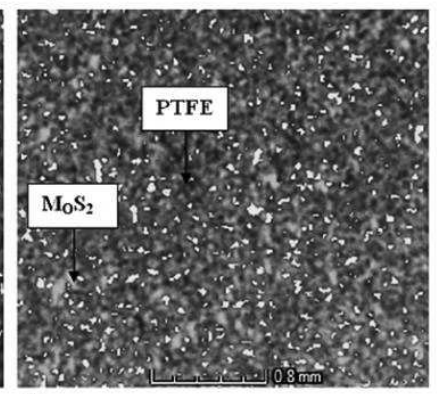

h)

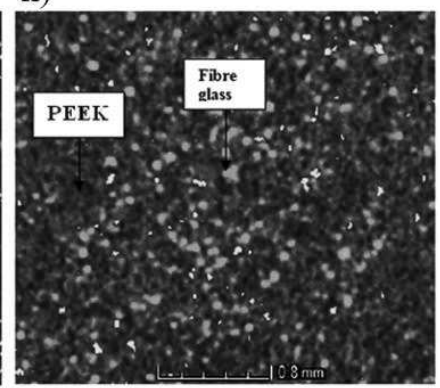

Fig. 5 Images of pores: a) PE with $\left.M_{O} S_{2}, b\right)$ PA6-G with mineral oil, c) PPS with fibre glass, d) PTFE with graphite e) POM with aluminium, $f$ ) PTFE with $M_{O} S_{2}, g$ ) PTFE with bronze, h) PEEK with glass fibre

\subsection{Compression test}

The compression plots were used to determine compressive strength, stress yield and Young's modulus of the analysed composite materials. The data, which have been substituted into relevant equations, are listed in Tab. 1.

Tab. 1 Comparison of parameters determined in compressive tests

\begin{tabular}{c|c|c|c|c|c|c}
\hline Composite material & $\begin{array}{c}\mathrm{S}_{0} \\
{\left[\mathrm{~mm}^{2}\right]}\end{array}$ & $\begin{array}{c}\mathrm{F}_{\mathrm{c}} \\
{[\mathrm{N}]}\end{array}$ & $\begin{array}{c}\mathrm{R}_{\mathrm{c}} \\
{[\mathrm{MPa}]}\end{array}$ & $\begin{array}{c}\mathrm{F}_{\text {plc }} \\
{[\mathrm{N}]}\end{array}$ & $\begin{array}{c}\mathrm{R}_{\text {plc }} \\
{[\mathrm{MPa}]}\end{array}$ & $\begin{array}{c}\mathrm{E} \\
{[\mathrm{MPa}]}\end{array}$ \\
\hline PE with $\mathrm{M}_{\mathrm{O}} \mathrm{S}_{2}$ & 55.9 & 19872.8 & 334.5 & 6500.0 & 116.3 & 436.4 \\
\hline PA6-G with mineral oil & 55.9 & 14263.4 & 241.2 & 2125.0 & 38.0 & 371.9 \\
\hline PTFE with bronze & 55.4 & 14694.5 & 256.3 & 1000.0 & 18.0 & 370.0 \\
\hline PTFE with graphite & 56.2 & 3759.6 & 65.3 & 500.0 & 8.9 & 30.5 \\
\hline POM with Al & 55.5 & 11248.3 & 193.7 & 4000.0 & 72.0 & 280.3 \\
\hline PTFE with $\mathrm{M}_{0} \mathrm{~S}_{2}$ & 54.6 & 11567.7 & 208.1 & 3500.0 & 64.1 & 296.5 \\
\hline PPS with glass fibre & 56.1 & 19833.1 & 339.8 & 6000.0 & 107.0 & 483.3 \\
\hline PEEK with glass fibre & 56.6 & 14076.8 & 240.4 & 2000.0 & 44.2 & 356.6 \\
\hline
\end{tabular}

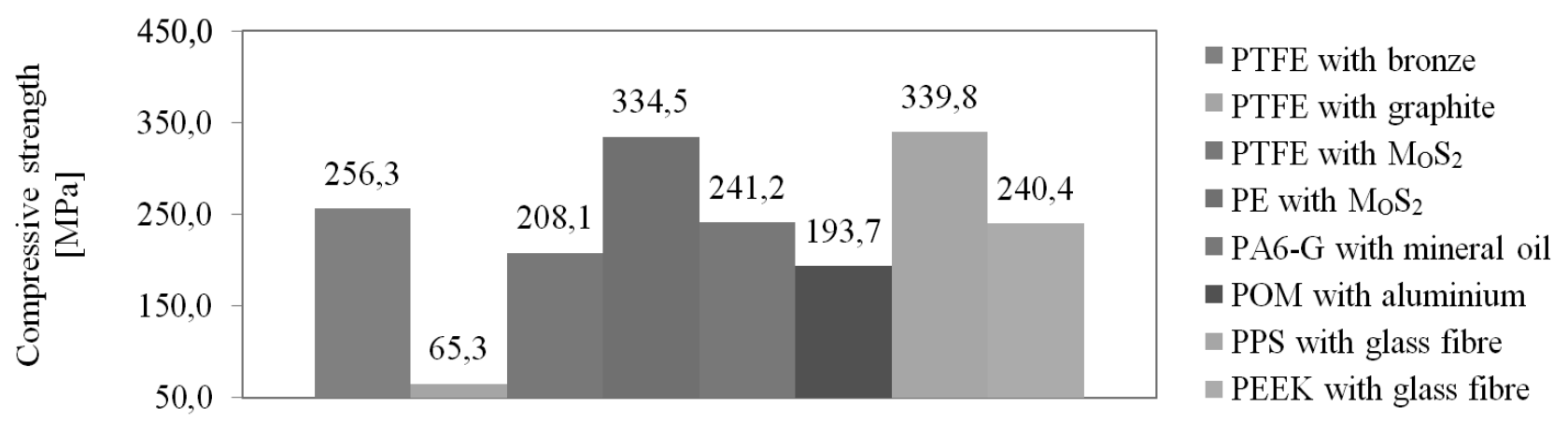

Fig. 6 Compressive strength of the analysed composite materials

Fig. 6 shows the results of compressive strength of the analysed composite materials. The highest compressive strength was obtained for PE with $\mathrm{M}_{\mathrm{o}} \mathrm{S}_{2}$ and PPS with glass fibre. Considering the group of PTFE-matrix composite materials, the highest $R_{c}$ was obtained for the composite material reinforced with bronze. PTFE with graphite has the lowest compressive strength. There is a 5-fold difference between the compressive strength of PE with $\mathrm{M}_{\mathrm{o}} \mathrm{S}_{2}$ and that of the aforementioned Teflon-based composite. The other composite materials have the mean compressive strength of $200 \mathrm{MPa}$. 


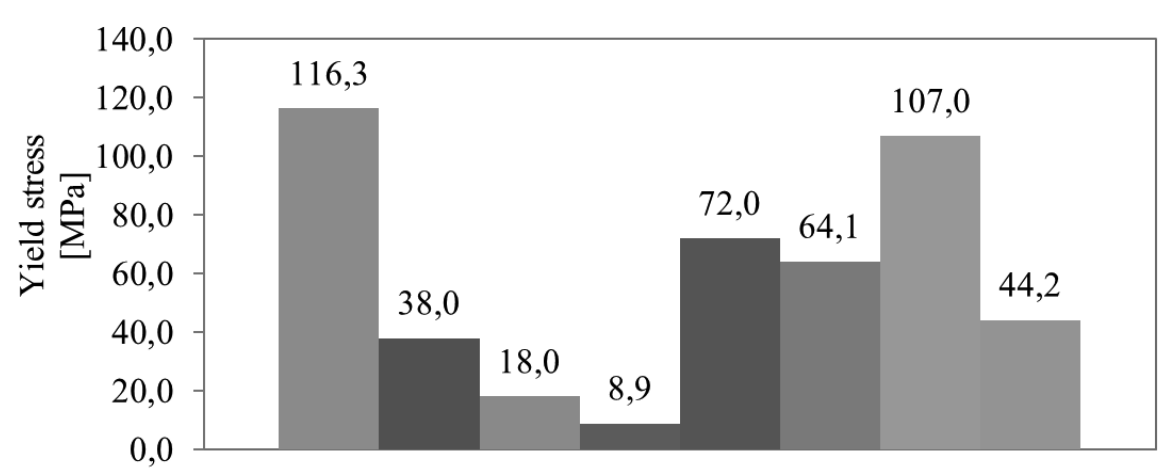

Fig. 7 Yield stress of the analysed composite materials

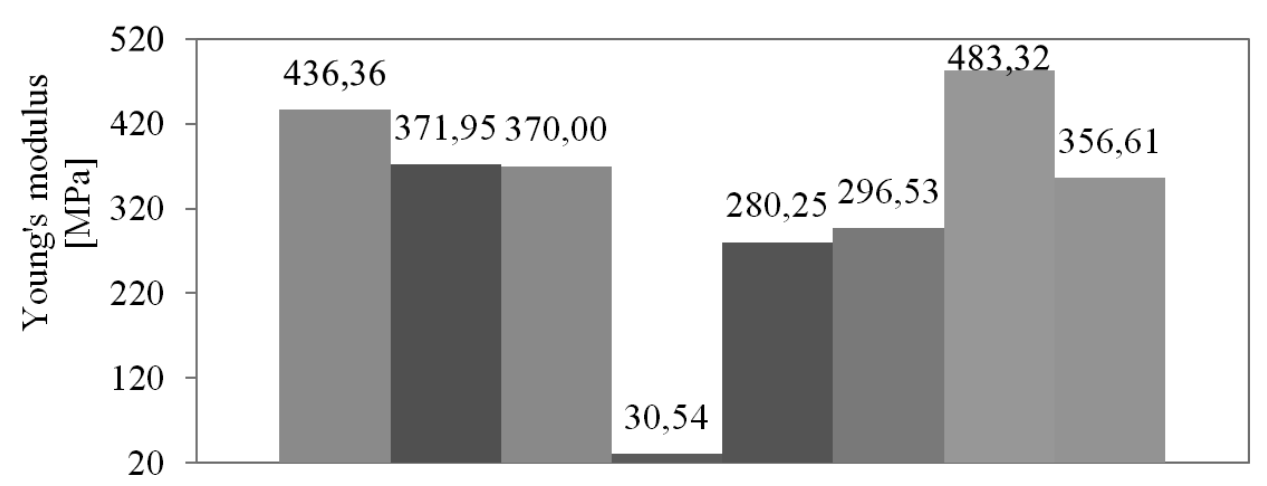

Fig. 8 Young's modulus of the analysed composite materials

(A)
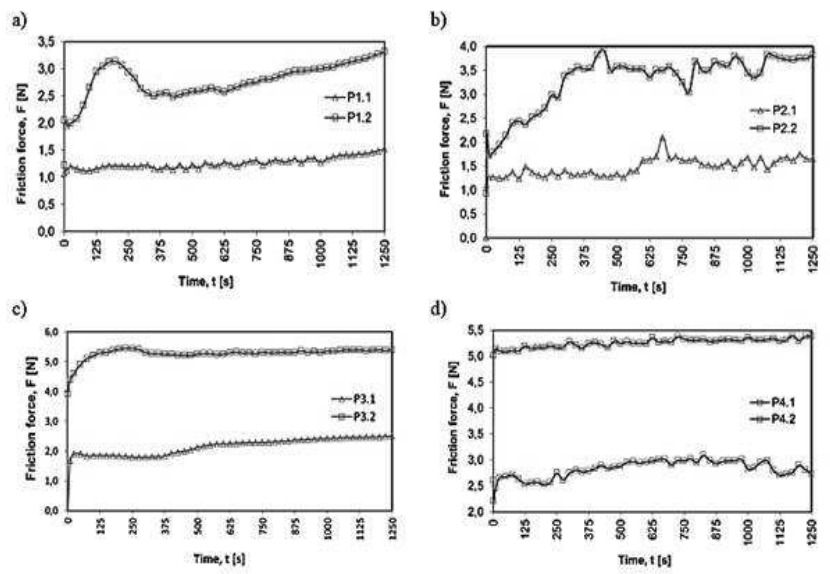

(C)
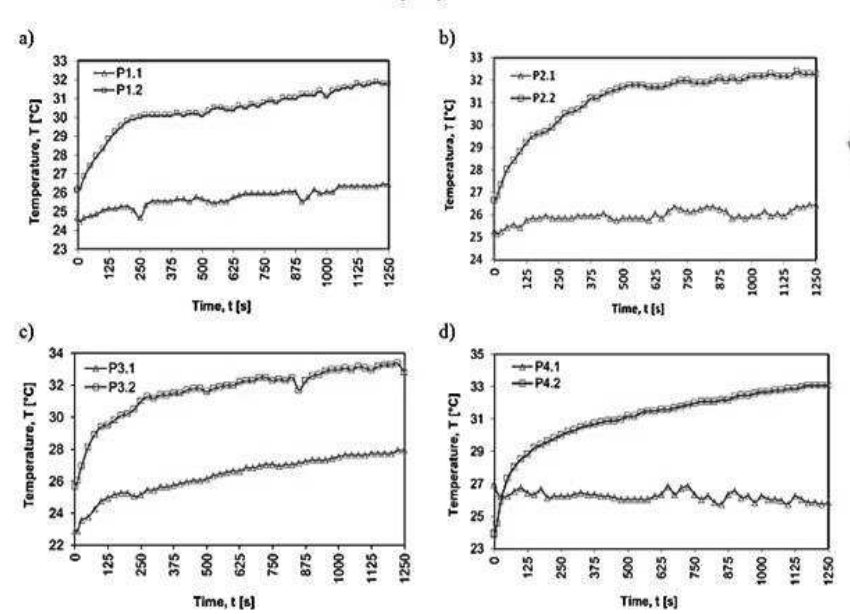

(B)
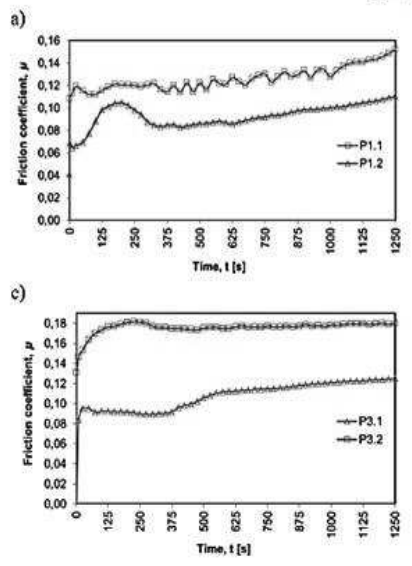

(D)
- PE z MOS2

- PA6-G z olejem

- PTFE $\mathrm{z}$ brązem

- PTFE $z$ grafitem

- POM $\mathrm{z}$ aluminium

- PTFE z MOS2

- PPS z włóknem szklanym

- PEEK z włóknem szklanym
PE with $\mathrm{MOS}_{2}$

- PA6-G with mineral oil

- PTFE with bronze

- PTFE with graphite

- POM with aluminium

PTFE with $\mathrm{MOS}_{2}$

- PPS with glass fibre

- PEEK with glass fibre
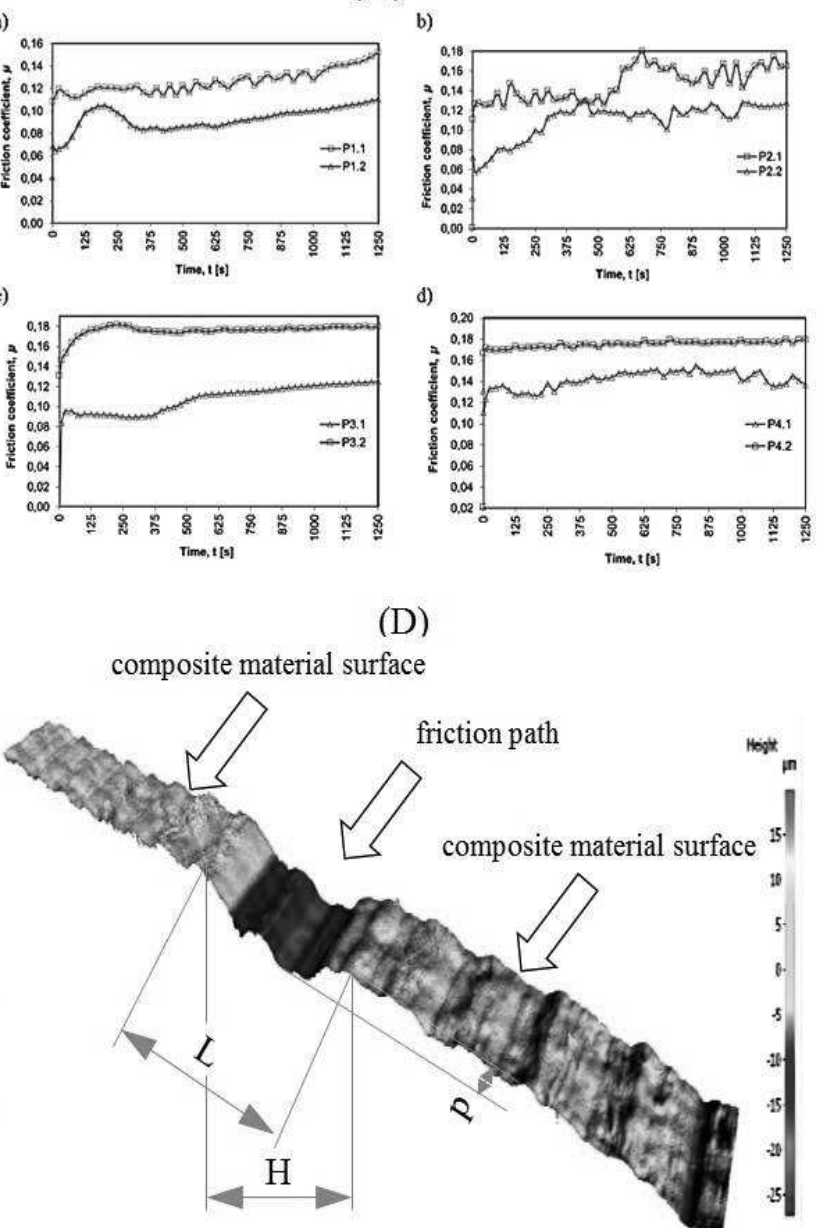

Fig. 9 Friction force $(A)$, friction coefficient $(B)$, temperature near friction node $(C)$ and friction path $(D)$, versus time t: a) PA6-G with mineral oil (samples P1.1 and P1.2), b) POM with aluminium (samples P2.1 and P2.2), c) PTFE with bronze (samples P3.1 and P3.2), d) PTFE with graphite (samples P4.1 and P4.2). 
Fig. 7 shows the yield stress results of the tested composite materials, determined based on the compressive strength plots. According to the data provided by Plastics Group [24], PE with $\mathrm{M}_{\mathrm{O}} \mathrm{S}_{2}$ has the highest yield stress. An equally satisfactory result - $107 \mathrm{MPa}$, was achieved by PPS with glass fibre. The glass fibre-reinforced PEEK has the yield stress below $50 \mathrm{MPa}$. POM with aluminium shows the highest difference between the yield stress of the polymer itself (42 $\mathrm{MPa}$ [24]) and the result of this study (72 MPa). Considering the PTFE-matrix composites, the highest yield stress is exhibited by the polymer composite reinforced with molybdenum disulphide (64.1 $\mathrm{MPa}$ ). Like in the case of compressive strength, PTFE with graphite has the lowest yield stress.

Analysing the results in Fig. 8 it can be observed that PPS with glass fibre and PE with $\mathrm{M}_{\mathrm{O}} \mathrm{S}_{2}$ undergo the smallest deformation under compressive load. Similar values of Young's modulus (355-370 MPa) were obtained for PA6-G with mineral oil, PTFE with bronze and PEEK with glass fibre. POM with $\mathrm{Al}$ and PTFE with $\mathrm{M}_{\mathrm{O}} \mathrm{S}_{2}$ have similar values of Young's modulus, amounting to approx. $280 \mathrm{MPa}$. PTFE with graphite undergoes the highest elastic deformation under compressive load - its Young's modulus is $31 \mathrm{MPa}$.
Fig. 9 shows selected results of the assessment of tribological properties of the investigated friction pairs. The plots show both the friction force variations as well as the determined friction coefficients $\mu$ of the analyzed kinematic pairs. The temperature in the vicinity of the friction node was determined in the tests too. The mean temperature during friction was: $\mathrm{T}\left[{ }^{\circ} \mathrm{C}\right]|24.5| 25.9|24.8| 26.8$ |23.1 26.4 |25.0 |24.2|, respectively. The maximum temperature was $33^{\circ} \mathrm{C}$.

Fig. 9. shows the microscopic image of the friction path used for determining linear and volumetric wear. Tab. 2 lists the friction coefficients, loads and linear displacement values describing wear in the friction zone.

The experimental results demonstrate that, out of all tested materials, PA6-G with mineral oil is definitely best suited for thin anti-friction coatings; if, however, entire elements of the friction node are to be made from a composite material, it is better to use PTFE with the addition of bronze or graphite. The study has demonstrated that polymer composites can be an alternative to traditional construction materials. This is confirmed by the obtained results and the general reliability of structures made of composite materials.

Tab. 2 Comparison of linear displacements and friction coefficients

\begin{tabular}{l|c|c|c|c|c|c|c|c} 
& $\begin{array}{c}\text { PA6-G } \\
\text { with mi- } \\
\text { neral oil }\end{array}$ & $\begin{array}{c}\text { POM } \\
\text { with } \\
\text { alumi- } \\
\text { nium }\end{array}$ & $\begin{array}{c}\text { PTFE } \\
\text { with } \\
\text { bronze }\end{array}$ & $\begin{array}{c}\text { PTFE } \\
\text { with } \\
\text { graphite }\end{array}$ & $\begin{array}{c}\text { PA6-G } \\
\text { with mi- } \\
\text { neral oil }\end{array}$ & $\begin{array}{c}\text { POM } \\
\text { with } \\
\text { alumi- } \\
\text { nium }\end{array}$ & $\begin{array}{c}\text { PTFE } \\
\text { with } \\
\text { bronze }\end{array}$ & $\begin{array}{c}\text { PTFE } \\
\text { with } \\
\text { graphite }\end{array}$ \\
\hline Specimen/parameter & P1.1 & P2.1 & P3.1 & P4.1 & P1.2 & P2.2 & P3.2 & P4.2 \\
\hline Load $[\mathrm{N}]$ & \multicolumn{2}{|c|}{10} & \multicolumn{2}{|c|}{20} & & \multicolumn{2}{|c}{30} \\
\hline Displacement, $\mathrm{p}[\mu \mathrm{m}]$ & 14.6 & 2.1 & 6.7 & 0.7 & 1.2 & 2.9 & 6.4 & 8.4 \\
\hline Frict.coefficient, $\mu$ & 0.12 & 0.15 & 0.11 & 0.141 & 0.09 & 0.11 & 0.175 & 0.175 \\
\hline
\end{tabular}

\section{Conclusions}

Polyethylene (PE) with molybdenum disulphide $\left(\mathrm{MoS}_{2}\right)$ has the highest hardness $(29.3 \mathrm{HV} 2)$ and relatively low porosity $(12.41 \%)$. In terms of compressive strength it is only surpassed by polyphenylene sulphide (PPS) with glass fibre (340 MPa). Compared to the other tested materials, $\mathrm{PE}$ with $\mathrm{M}_{\mathrm{O}} \mathrm{S}_{2}$ exhibits the best operating properties. For this reason, it is recommended that this composite material be used for producing structural elements operating under high loads. The study has shown that the considerably high stresses cause neither drastic changes to its microstructure nor generate plastic strains. Cast polyamide (PA6-G) with mineral oil is best suited for use in light industry. Compared to PTFE with bronze, it has lower compressive strength yet similar hardness (9.2 HV2 on average). What is more, PA6-G is less expensive than PTFE. PTFE with bronze is characterized by a small pore volume $(4.17 \%)$, which has a positive effect on the strength properties of this composite material. Compared to natural Teflon [23], the addition of bronze has significantly improved the mechanical properties of this composite (hardness and yield stress). PTFE with graphite has the least desired properties out of all tested materials. It has exceptionally low compressive strength (65.3 MPa) and deformability (as proven by the imprints left on the surface in hardness testing). These low mechanical properties are due to the material's structure, particularly its high porosity $(9.16 \%)$. Polyacetal (POM) with aluminium (Al) exhibits high hardness (23.3 HV2), which is comparable to the results obtained for PE with $\mathrm{M}_{\mathrm{O}} \mathrm{S}_{2}$ and PPS with glass fibre. In addition, it has a smaller pore volume. Its compressive strength (194 MPa) is, however, considerably lower and thus, generally, quite insignificant when compared to the other analyzed plastics. PTFE with $\mathrm{M}_{\mathrm{O}} \mathrm{S}_{2}$ exhibits considerably high compressive strength (208 MPa). In terms of its operating properties, it resembles POM with Al. Both composite materials perform well in surface treatment. When selecting between the two materials, one must consider not only permissible changes in their microscopic structure, but also their price (PTFE is more expensive). Polyphenylene sulphide (PPS) reinforced with glass fibre is suitable for use in the machine-building industry. It has the highest compressive strength and low deformability under stress amounting to $480 \mathrm{MPa}$. Compared to PE with $\mathrm{M}_{\mathrm{O}} \mathrm{S}_{2}$, PPS has similar porosity $(9.1 \%)$ yet is less expensive. The results of polyether ether ketone (PEEK) with glass fibre are relatively comparable with those obtained for the other tested composite materials. It has the lowest porosity $(2.12 \%)$, which, however, does not significantly 
improve the mechanical properties of this composite. In terms of compressive strength, this material is similar to PA6-G with mineral oil and PTFE with bronze. Although manufacturers recommend its use for structures operating under high loads, the test results reveal that some other material should be used for this purpose. The study has also demonstrated that all the tested composite materials have very good tribological properties that are particularly desired in the design of sliding elements. This is proved by the low coefficients of friction $(\mu)$ obtained for the tested friction pairs. The tests have shown that the composite materials reinforced with mineral oil and aluminium oxide $\left(\mathrm{Al}_{2} \mathrm{O}_{3}\right)$ retain very good tribological properties. This is confirmed by the low values of linear wear and friction coefficients. Similar results were obtained in $[2,4,8,10,12]$, in which polymer composites were tested at room temperature under the loads of 10,20 and $30 \mathrm{~N}$ (the best results were obtained for PA6-G with mineral oil, out of all tested polymer composites). It has been observed that the tested parameters, i.e. the friction force F, the temperature near the friction node $\mathrm{T}$, and the friction coefficient $\mu$, are significantly affected by the applied load $(10 \mathrm{~N}, 20 \mathrm{~N}, 30 \mathrm{~N})$. The coefficient of friction ranges between 0.11 and 0.175 , which can be regarded as a very good result, especially given the fact that the composite materials were loaded with a concentrated force exerted by a hard material $\left(\mathrm{Al}_{2} \mathrm{O}_{3}\right)$. Therefore, it can be claimed that the analyzed composite materials can carry high loads exerted by a much harder material, while at the same time retaining very good tribological properties, even for such friction pairs as steel-graphite and steel-glass. On increasing the external load, all analyzed operating parameters of the friction process increase too. Among the tested polymer composites, the best results were obtained for PA6-G with mineral oil. PTFE-matrix composites despite their good results of the friction coefficient $\mu-$ are less desired than POM with aluminium because their use is less cost-effective.

\section{References}

[1] FRIEDRICH, K. (2018). Polymer composites for tribological applications. In: Advanced Industrial and Engineering Polymer Research, Vol. 1, No. 1, pp. 3 - 39. ScienceDirect, Elsevier B.V., Netherlands.

[2] NEIS, P. D., FERREIRA, N. F., POLETTO, J. C., SUKUMARAN, J., ANDÓ, M., ZHANG, Y. (2017). Tribological behaviour of polyamide-6 plastics and their potential use in industrial applications. In: Wear, Vol. 376 - 377, Part B, pp. 1391 - 98. ScienceDirect, Elsevier B.V., Netherlands.

[3] SONG, F., WANG, Q., WANG, T. (2016). The effects of crystallinity on the mechanical properties and the limiting PV (pressure $\times$ velocity) value of PTFE. In: Tribology International, Vol. 93, Part A, pp. 1 - 10. ScienceDirect, Elsevier B.V. Netherlands.
[4] KERESZTES, R., ODROBINA, M., NAGARAJAN, R., SUBRAMANIAN, K., KALACSKA, G., SUKUMARAN, J. (2019). Tribological characteristics of cast polyamide 6 (PA6G) matrix and their composite (PA6G SL) under normal and overload conditions using dynamic pin-on-plate system. In: Composites Part B: Engineering, Vol. 160, pp.119 - 130. ScienceDirect, Elsevier B.V., Netherlands.

[5] LI, H., MA, Y., LI, Z., CUI, Y., WANG, H. (2018). Synthesis of novel multilayer composite microcapsules and their application in self-lubricating polymer composites. In: Composites Science and Technology, Vol. 164, pp. 120 - 128. ScienceDirect, Elsevier B.V., Netherlands.

[6] LIU, Y., XU, N., WANG, Y., YAO, Y., XIAO, H., JIA, J., LV, H., ZHANG, D. (2019). Preparation and tribological properties of hybrid PTFE/Kevlar fabric self-lubricating composites. In: Surface and Coatings Technology, Vol. 361, pp. 196 - 205. ScienceDirect, Elsevier B.V., Netherlands.

[7] LI, H., LI, S., LI, F., LI, Z.,WANG, H. (2018). Fabrication of $\mathrm{SiO}_{2}$ wrapped polystyrene microcapsules by Pickering polymerization for self-lubricating coatings. In: Journal of Colloid and Interface Science, Vol. 528, pp. 92 - 99. ScienceDirect, Elsevier B.V., Netherlands.

[8] KARAMI, P., SHOJAEI, A. (2017). Improvement of dry sliding tribological properties of polyamide 6 using diamond nanoparticles. In: Tribology International, Vol. 115, pp. 370 - 377. Elsevier B.V. Netherlands.

[9] KARATAS, E., GUL, O., KARSLI, N.G.,YILMAZ, T. (2019). Synergetic effect of graphene nanoplatelet, carbon fiber and coupling agent addition on the tribological, mechanical and thermal properties of polyamide 6,6 composites. In: Composites Part B: Engineering, Vol. 163, pp. 730 - 739. Elsevier B.V. Netherlands.

[10] ZHOU, S., WANG, J., WANG, S., MA, X., HUANG, J., ZHAO, G., LIU, Y. (2018). Facile preparation of multiscale graphene-basalt fibre reinforcements and their enhanced mechanical and tribological properties for polyamide 6 composites. In: Materials Chemistry and Physics, Vol. 217, pp. 315 - 322. ScienceDirect, Elsevier B.V., Netherlands.

[11] YOU, Y.-L., LI, D.-X., SI, G.-J., DENG, X. (2014). Investigation of the influence of solid lubricants on the tribological properties of polyamide 6 nanocomposite. In: Wear, Vol. 311, No. $1-2$, pp. 57 - 64. ScienceDirect, Elsevier B.V., Netherlands.

[12] ZHAO, L.-X., ZHENG, L.-Y., ZHAO, S.-G. (2006). Tribological performance of nano-Al2O3 reinforced polyamide 6 composites. In: Materials Letters, Vol. 60, No. 21 - 22, pp. 2590 - 2593. 
ScienceDirect,

Elsevier B.V., Netherlands.

[13] ZHOU, S., ZHANG, Q., WU, CH., HUANG, J. (2013). Effect of carbon fiber reinforcement on the mechanical and tribological properties of polyamide6/polyphenylene sulfide composites. In: $M a$ terials \& Design, Vol. 44, pp. 493 - 499. ScienceDirect, Elsevier B.V., Netherlands.

[14] ZSIDAI, L., DE BAETS, P., SAMYN, P., KALACSKA, G., VAN PETEGHEM, A.-P., VAN PARRYS, F. (2002). The tribological behaviour of engineering plastics during sliding friction investigated with small-scale specimens. In: Wear, Vol. 253, No. 5 -6, pp. 673 -88. ScienceDirect, Elsevier B.V., Netherlands.

[15] FEYZULLAHOGLU, E., SAFFAK, Z. (2008). The tribological behaviour of different engineering plastics under dry friction conditions. In: $M a$ terials \& Design, Vol. 29, No. 1, pp. $205-211$, ScienceDirect,

Elsevier B.V., Netherlands.

[16] PASHECHKO M., MONTUSIEWICZ J., DZIEDZIC K., JOZWIK, J. (2017). Multicriterion assessment of wear resistance of $\mathrm{Fe}-\mathrm{Mn}-\mathrm{C}-\mathrm{B}$ eutectic coatings alloyed with $\mathrm{Si}, \mathrm{Ni}$, and $\mathrm{Cr}$. In: Powder Metallurgy and Metal Ceramics, Vol. 56, No. 5 -6, pp. 316 - 322. Springer. Switzerland.

[17] UNAL, H., MIMAROGLU, A. (2003). Friction and wear behaviour of unfilled engineering thermoplastics. In: Materials \& Design, Vol. 24, No. 3, pp. 183 - 187. ScienceDirect, Elsevier B.V. Netherlands.

[18] JÓZWIK, J., OSTROWSKI, D., MILCZARCZYK, R., KROLCZYK, G.-M. (2018). Analysis of relation between the 3D printer laser beam power and the surface morphology properties in Ti-6Al-4V titanium alloy parts. In: Journal of The Brazilian Society of Mechanical Sciences and Engineering, Vol. 40:215, pp.1 - 10, Springer. Switzerland.

[19] JOZWIK, J. (2018). evaluation of tribological properties and condition of Ti6AI4V titanium alloy surface. In: Tehnicki Vjesnik - Technical Gazette,
Vol. 25, Suppl. 1, pp. 170 - 175. Mechanical Engineering Faculty in Slavonski Brod (MEFSB), Josip Juraj Strossmayer University of Osijek. Croatia.

[20] DZIEDZIC, K., ZUBRZYCKA-WRÓBEL, J., JÓZWIK, J., BARSZCZ, M., SIWAK, P., CHAŁAS, R. (2016). Research on tribological properties of dental composite materials. In: Advances in Science and Technology Research Journal, Vol. 10, No. 32, pp. 144 - 149. SIMP in Lublin, Poland

[21] PASHECHKO, M., I., DZIEDZIC, K., MENDYK, E., JOZWIK, J. (2018). chemical and phase composition of the friction surfaces Fe-MnC-B-Si-Ni-Cr hardfacing coatings. In: Journal of Tribology, Vol. 140, No. 2, pp. 1- 5. The American Society of Mechanical Engineers, USA.

[22] DZIEDZIC, K, JOZWIK, J., BARSZCZ M. (2016). The assessment of tribological properties and the condition of the surface of tool steel for hot work 55NiCrMoV6 subjected to the process of friction, In: Manufacturing Technology, Vol. 16, No. 1, pp. 69 - 76. FME JEPU, Usti nad Labem, Czech Republic.

[23] MIZERA, ¿̌., HRABĚ, P., MÜller, M., HERÁK, D. (2016). Creep behaviour of the polymer composite with false banana's fibres (ensete ventricosum). In: Manufacturing Technology, Vol. 16, No. 1, pp. 188 - 192. FME JEPU, Usti nad Labem, Czech Republic.

[24] MÜlLER, M., CIDLINA, J., DĚDIČOVÁ, K., KROFOVÁ A. (2015). Mechanical properties of polymeric composite based on aluminium microparticles. In: Manufacturing Technology, Vol. 15, No. 4, pp.624 - 628. FME JEPU, Usti nad Labem, Czech Republic.

[25] MÜlleR, M., RUGGIERO, A., VALÁŠEK, P. (2017). Mechanical characterisation of metal/polymeric composite waste/metal sandwich panel. In: Manufacturing Technology, Vol. 17, No. 4, pp. 530 - 536. FME JEPU, Usti nad Labem, Czech Republic. 